\title{
Risk Assessment for Intimate Partner Violence: How can the Police Assess Risk?
}

\begin{abstract}
The use of risk assessment tools by frontline police for intimate partner violence has the potential to make a difference to policing. In this paper, the key aspects of intimate partner violence risk assessment are outlined critically with a particular emphasis on how they can be used in practice. Two, evidence-based, exemplars are reviewed. These are the Ontario Domestic Abuse Risk Assessment (ODARA), an example of the actuarial approach, and the Brief Spousal Assault Form for the Evaluation of Risk (B-SAFER), an example of the structured professional judgement approach. In addition, the victim giving his or her own appraisal of risk is discussed. All three approaches have some validity when administered properly but practical factors reduce this validity. The content of the risk assessment tools are outlined and practical concerns such as training, time to administer, reliability, validity, and the overlap of intimate partner violence with other forms of offending are discussed. A balanced overview of the strengths, weaknesses and future potential of intimate partner violence risk assessment is provided.
\end{abstract}

Key words: Intimate Partner Violence; Domestic Violence; Policing; Risk Assessment. 


\section{Risk Assessment for Intimate Partner Violence: How can the Police Assess Risk?}

Intimate partner violence is a persistent problem all around the world that accounts for a great deal of police work (Devries et al., 2013). Robinson, Myhill, Wire, Roberts and Tilley (2016) found that between four and seven percent of calls to police concerned intimate partner violence. Intimate partner violence can have a variety of trajectories (Hilton \& Eke, 2016; Robinson, Myhill, Wire, Tilley, \& Roberts, 2016). Some cases of intimate partner violence may be one-off events at the end of a relationship. Other cases may be part of ongoing violence that is increasing in frequency and severity. A few may involve such extreme levels of violence that the victim is killed. If police could determine who will escalate their violence, who will never offend again, and who may kill their partner if not stopped, then police would be able to use their resources to the most effect (Ariza, Robinson, \& Myhill, 2016).

Research suggests that not all intimate partner violence offenders are the same. For example, Holtzworth-Munroe and Stuart (1994) proposed a typology of three different types of domestically violent men with increasing levels of intimate partner violence across the three categories: 'family only' offenders were the least violent; 'dysphoric/borderline' were more violent; and, those who were 'generally violent/antisocial' were the most violent of all. This is a finding that has been shown in several empirical studies (e.g., Johnson et al., 2006; Serie, van Tilburg, van Dam, \& de Ruiter, 2017; for a review of typologies see Ali, Dhingra, $\&$ McGarry, 2016). In one example of the disproportionate contribution of a small number of offenders, Sherman and colleagues found that two percent of offenders were responsible for $50 \%$ of the harm caused by intimate partner violence in Western Australia (Sherman, Bland, House, \& Strang, 2016). The implication of these studies is that focusing resources on those offenders who are most violent may be the most effective way of reducing violence. Of course, these studies were retrospective analyses, which looked back over offending histories 
and while is easier to identify characteristics of people after they have offended than beforehand, it does illustrate the potential for risk assessment to identify those who may cause the most intimate partner violence (Bland \& Ariel, 2015).

In this paper the fundamental principles of risk assessment for intimate partner violence are discussed; risk assessment tools that are available to assist assessing risk of intimate partner violence are described; and the advantages and disadvantages of various risk assessment approaches are reviewed. This information is important for those working in policing so they can make informed decisions about the use of risk assessment tools for intimate partner violence. For the purposes of this paper, intimate partner violence is defined as attempted, threatened, or actual violence committed against a partner or romantic partner (former or past), that could take the form of physical, sexual, and emotional abuse as well as intimidation and control (see Heyman, Slep, \& Forman, 2015; Heyman et al., 2018). Other terms are used in other papers, such as domestic abuse (e.g., Bland \& Ariel, 2015) or domestic violence (e.g., Berk, Sorenson, \& Barnes, 2016). These may include similar, overlapping, behaviours but the term intimate partner violence is used here because it most accurately describes the behaviours of interest, as well as the fact that definitions exist that allow for it to be reliably coded (again see Heyman, Slep, \& Forman, 2015; Heyman et al., 2018).

\section{Risk assessment - why bother?}

Risk assessment is appealing for a variety of reasons. First, as mentioned earlier, risk assessment allows limited resources to be focused on those who are most in need. Police will never have as much resources as they could possibly need, hence risk assessment allows limited resources to be targeted. This is consistent with Risk-Needs-Responsivity theory (Andrews, Bonta, \& Hoge, 1990), a theory that has a strong evidence base for the effective 
management of offenders within correctional environments (Andrews \& Bonta, 2017; Ogloff \& Davies, 2004). The basic premise of this approach is that you target the most resources to those who are at highest 'risk'. For example, a man may be high risk of committing intimate partner violence because he thinks it is acceptable to hit women when intoxicated by alcohol - and he is drunk a lot of the time. Next, attention is paid to the criminogenic 'needs' (e.g., psychological problems) of the man, that is, what needs to change to stop him offending. In the example case, the criminogenic needs might be alcohol use and attitudes towards using intimate partner violence. The final aspect in the Risk-Needs-Responsivity approach is responsivity. This concerns what is most likely to work for the man to address his needs and reduce his offending. For example, a great deal of evidence suggests a cognitive-behavioural approach is likely to be effective with offenders (Ogloff \& Davies, 2004) and this may be a useful approach to changing the man's alcohol use and attitudes towards intimate partner violence. Our example offender may also need motivation to change. Factors that may motivate him include a desire to avoid a future jail sentence, a desire to have a better life and a desire to have more successful relationships (Ogloff \& Davies, 2004).

There are other advantages to a risk assessment approach. Many frontline police are inexperienced, having recently left police training. This means they have little direct experience of responding to intimate partner violence incidents. Risk assessment tools may allow them to benefit from the experience of those who created the tools. In turn this may help them make better decisions. Furthermore, the use of a risk assessment tool may allow for more effective communication between different police units and other areas, such as social services, because of a consistency of language and shared definition of risk. A risk framework can also provide justification for decisions and an auditable structure. This may be particularly important if negative outcomes occur following police involvement, or because of a lack of police involvement. 


\section{What is risk and what do police want from a risk assessment tool?}

There are many characteristics that are desirable in a risk assessment tool. The most important is validity, that is, to say the tool should be able to predict the behaviour that is intended (Gregory, 2011). In the context of intimate partner violence, determining if violence has occurred to determine validity is difficult. An ideal form of behaviour to measure validity might be "actual, attempted, or threatened physical harm of a current or former intimate partner" (Kropp, Hart \& Belfrage, 2005, p. 1). However, it is difficult to get accurate data about these rates because the crime is often not reported and occurs behind closed doors. Other measures of validity can be used instead. These include calls to the police or obvious, extreme, levels of violence such as homicide (Campbell, Webster, \& Glass, 2009). These are clearly not perfect measures because so many offences are missing but are often all the data that are available to determine validity.

A precondition to validity is reliability. In the context of risk assessment tools, reliability has a specific definition. It is that a risk tool is scored consistently (Gregory, 2011). For example, if one person uses a risk assessment tool and scores someone as 'high' whilst another person scores the same person, with the same tool and same information, as 'low' then then tool is unreliable. In turn, this means the tool cannot possibly be consistently valid because it is not being consistently scored.

As well as reliability and validity, it is important that the tool can be used in a practical way to discriminate between different levels of risk. For example, if everyone is assigned a 'high risk' category, regardless of actual risk, resources cannot be focused on those who need them the most. Indeed, assigning people who are low risk to a high risk category by mistake and giving them a great deal of police attention might be construed as disproportionate and harassment. For this reason, an effective risk assessment tool should be 
able to effectively discriminate between high (i.e., those who score high are the most likely to reoffend), medium and low risk individuals (i.e., those with a low score are least likely to reoffend). These risk assessments will also be contingent on situational factors as risk may change as situations change. For example, someone might be of low risk when they are starting a relationship but high risk when the relationship is ending. This topic is discussed further in a later section.

A final requirement for an effective risk assessment tool is to have norms to understand what a risk score means. Norms, in the context of risk assessment, indicate how many people in each category are likely to reoffend. Terms like 'high' and 'low' can have different meanings depending on the tool (for an interesting proposal for standardising the meaning of risk terms see Hanson et al., 2017). As an example, Hilton et al. (2004) provide data on recidivism rates related to risk score for the Ontario Domestic Abuse Risk Assessment (ODARA), a tool that is described in more detail later. They report that six percent of intimate partner violence offenders scored between 7 and 13 on the ODARA and their recidivism rate was $70 \%$ over the next 4.79 years. In contrast, $11 \%$ of people scored zero on the ODARA and their recidivism rate was $5 \%$ over 4.79 years. This information can be used to determine where resources are most needed. In this instance, prioritising those with a score between 7 and 13 over those with a score of zero would seem warranted. The fact that only six percent are in this category may mean it is a sufficiently small number of people that there are enough resources.

Collecting norms is time-consuming and expensive. As a consequence few intimate partner violence risk assessments have adequate norms. Further, when there are norms, these are often not applicable to the situation that the tool is being used. A risk assessment that has norms for the United States may have different norms in another country, for example, Liem, Barber, Markwalder, Killias and Nieuwbeerta (2011) found homicide-suicide rates, usually 
involving intimate partner violence, to be more than four times higher in the United States than the Netherlands. Crime rates, and in turn the usefulness of norms, can vary greatly from place to place. This means that relevant, local, norms are necessary. Otherwise terms such as high or low risk have no objective meaning.

\section{Risk assessment for intimate partner violence}

There are a number of risk assessment tools that can be used by frontline police. Many police services have devised their own risk assessment procedures or used parts of existing tools. Risk assessments can be broadly categorised as professional judgement or 'gut' approaches, actuarial tools and structured professional judgement. Professional judgment (sometimes called unstructured judgement) has historically been the way in which police assess risk of intimate partner violence. The police officers at the scene decide, based on their experience and the information that is available to them, the level of risk. When this professional judgment approach has been used with offenders generally, by psychiatrists and psychologists, it is often inaccurate (Quinsey, Harris, Rice, \& Cormier, 1998; Ward \& Beech, 2015). This seems to be because of the biases the assessors might have or because the assessors are not looking for the most important information to guide the assessment of risk. This has led to a shift away from relying on only professional judgement towards actuarial and structured professional judgment approaches. It is worth mentioning, however, that Nicholls, Pritchard, Reeves, and Hilterman (2013) found no empirical evidence that anyone had tested the accuracy of unstructured judgements in the context of intimate partner violence. This would seem an oversight.

Actuarial approaches, in contrast to professional judgement, remove personal decisions entirely. Actuarial risk is usually calculated from large datasets, analyzed for factors that are related to risk. These factors are then used in a risk assessment tool whereby, 
for example, 10-20 standardised items or questions are assessed for each case. An analogy of this approach is how car insurance premiums are calculated. For car insurance, factors such as the age of the driver and their accident history are used to estimate risk and in turn the cost of insurance. An alternative approach to pure professional judgement or the actuarial approach, is the structured professional judgement approach. With this approach, the assessor is guided as to what information to collect and assess before making his or her own decision about risk.

\section{What is known about risk assessment tools for assessing risk of intimate partner violence?}

There are a number of risk assessment tools for intimate partner violence for professionals (for reviews see, Hanson, Bourgon, \& Helmus, 2007; Messing \& Thaller, 2013; Nicholls, Pritchard, Reeves, \& Hilterman, 2013; Wheller \& Wire, 2014). However, the focus of this paper is tools the police can use, so assessments like the Spousal Assault Risk Assessment (SARA; Kropp \& Hart, 2000) have not been included because they require qualifications and experience that few frontline police will be able to meet. For the purposes of this article exemplars of the three main approaches for risk assessment are given. These are the actuarial approach, the structured-professional judgement approach and the approach of asking victims themselves about how at risk they feel. In practice, there is an overlap between the three.

Actuarial Tools. The Ontario Domestic Abuse Risk Assessment (ODARA; Hilton, Harris \& Rice, 2010) was chosen as an exemplar of the actuarial approach as it is the actuarial tool with the strongest evidence base for use in predicting general intimate partner violence (see, for example, Wheller \& Wire, 2014). Arguably the Danger Assessment (DA; Campbell, Webster, \& Glass, 2009) or even the shortened version, the Lethality Assessment 
(Messing, Campbell, Sullivan Wilson, Brown, \& Patchell, 2017), could have been used. There is also substantial literature to support their use and the DA is similarly accurate in predicting re-offending to the ODARA (again see Wheller \& Wire, 2014). However, the DA is designed for predicting intimate partner homicide specifically, rather than intimate partner violence more generally, which is why the ODARA was used. Direct comparisons, 'like for like' are difficult across different studies due to the various methodologies used; some studies may look at offending over 12 months whilst others look at offending over five years. Further, some studies may use charges as evidence of reoffending while others use convictions or even simply allegations. For this reason, caution must be exercised when saying there are definite differences between risk assessment tools because they have not been compared with identical criteria in the same study.

The Ontario Domestic Abuse Risk Assessment (ODARA) is a 13-item tool for identifying the risk of future intimate partner violence for men who have already been identified as having committed at least one act of intimate partner violence (Hilton, Harris, \& Rice, 2010). The items are displayed in Table 1. The items require a review of police records as well as the most recent intimate partner violence incident and are as follows: has a prior domestic assault (against a partner or child) in police Record Management System (RMS); has a prior nondomestic assault (against anyone other than a partner or child) in RMS; has a prior sentence to a term of 30 days or more; has a prior failure on conditional release including bail, parole, probation, and no-contact order; threatened to harm or kill anyone during index offence; unlawful confinement of victim during index offence; victim fears repetition of violence; victim and/or offender have more than one child altogether; offender is in stepfather role in this relationship; offender is violent outside the home (to people other than a partner or child); offender has more than one indicator of a substance abuse problem; offender has ever assaulted victim when she was pregnant; and, victim faces at least one 
barrier to support. These items are scored as present or absent and then added up. If the score is seven or more the person is in the highest risk category.

The validity of the ODARA as indicated by 'Area Under the Curve' (AUC) is .67 with a confidence interval of .66 to .67 (Wheller \& Wire, 2014). This refers to 'Area Under the Receiver Operator Characteristic Curve' and is used to describe the accuracy with which a test discriminates between true positives (e.g., a man is predicted to commit an intimate partner violence offence and does so), false positives (e.g., a man is predicted to commit intimate partner violence offence but does not), true negatives (e.g., a man is predicted not to commit intimate partner violence offence and does not) and false negatives (e.g., a man is predicted not to commit intimate partner violence offence but does). If the AUC is .50 then this is simply chance responding and no different to guessing. An AUC of .56 can be considered small predictive validity, .64 medium predictive validity and .71 large predictive validity (Rice \& Harris, 2005). Thus, the ODARA has medium to large predictive validity.

Structured Professional Judgment. The Brief Spousal Assault Form for the Evaluation of Risk (B-SAFER) has the most substantial evidence base for a structured professional judgement tools used by police (Kropp \& Hart, 2004). It is an adaption of the SARA, a clinical tool modified so it can be used by police without the qualifications needed to administer the SARA (again the items are displayed in Table 1). A brief manual is provided that explains the rationale for each of 10 items and the scoring system (Kropp \& Hart, 2004). The items are: serious physical or sexual violence against partner; serious violent threats or thoughts about violence to partner; escalation of physical or sexual violence; violations of civil or criminal court orders; negative attitudes about intimate partner violence; other serious criminality; intimate relationship problems; employment or financial problems; substance abuse; and mental health problems. Each of the 10 items are coded for the present time and the past - essentially creating 20 items in total. For example, item one, 'serious 
physical or sexual violence against partner' would be coded for the most recent occurrence where police were involved and also past occurrences separately.

Items are scored as ' $\mathrm{Y}$ ' if there is evidence that an important, case-specific, risk factor is present. ' $\mathrm{P}$ ' if there is possible/partial evidence that an important, case-specific, risk factor is present. ' $\mathrm{N}$ ' if there is no evidence that an important, case-specific risk factor is present. There are anchored judgement scales that clarify the scoring. For example, regarding the item 'other serious criminality' the assessor is given the choice of three responses: ' $\mathrm{Y}$ ' the individual has engaged in other serious criminality'; ' $\mathrm{P}$ ' possible or partial evidence that the individual has engaged in other serious criminality, or the individual has engaged in less serious criminality; or, ' $\mathrm{N}$ ' the individual has not engaged in other serious criminality. The anchor helps clarify the item and reminds the officer of what is required for each score. Once all the items have been assessed the police officer is required to assess the need for case prioritisation, the risk of life-threatening violence, the risk of imminent violence, and who the likely victims may be (note: some researchers have scored the tool differently using 0,1 , or 2 instead of N, P, or Y [Storey, Kropp, Hart, Belfrage, \& Strand, 2014]).

The B-SAFER seems to have similar validity to the ODARA. For instance, a recent study in Sweden found an AUC of .65 but with a much larger confidence interval of .58 to .71 when officers' professional judgement of risk was used to predict risk of reoffending (Storey, Kropp, Hart, Belfrage, \& Strand, 2014). Although no conventional inter-rater reliability measures were reported, there must be good reliability to have this level of validity - that is to say the different police officers must have coded the B-SAFER reasonably well in order to get this AUC. Interestingly, when scores were simply added together, essentially using the tool as an actuarial tool rather than as structured professional judgement tool, the AUC was higher at .70 (with a confidence interval of .64 to .76). Other studies using the BSAFER are more difficult to interpret because offenders were treated differently depending 
on risk level (Belfrage \& Strand, 2012). For instance, those who are identified as high risk were given more supervision from police and so would be expected to offend less frequently than if they had not received this attention. Finally, it is not surprising that the ODARA and the B-SAFER are comparable in predictive validity - both share many of the same items.

Another structured professional judgment tool worth mentioning here is the Domestic Abuse, Stalking and Harassment and Honour-based violence risk identification, assessment and management model (DASH; Robinson, Myhill, Wire, Roberts, \& Tilley, 2016). The DASH is used by all police in England and Wales and there are a number of studies into the practicalities of using the DASH, referred to in another section, hence it is mentioned here. The DASH consists of 27 items that are scored primarily by asking the victim about the perpetrator (see Robinson, Myhill, Wire, Roberts, \& Tilley, 2016). The items were developed by amalgamating other tools that were in use around England and Wales, and with reference to the academic literature. For these reasons, many of the items that are used in the DASH overlap with those of the ODARA and the B-SAFER. The DASH items are also shown in Table 1 for comparison purposes. The DASH does not have a strong empirical base with regards to its validity, for example, Almond, McManus, Brian, and Merrington (2017) found that most of the items in the DASH do not predict future intimate partner violence

Victims as their own Risk Assessors. An alternative way of assessing risk is getting the victims to assess their own risk. Bowen (2011) reviewed six studies where victims of intimate partner abuse rated their own risk of re-abuse. As in many cases in this field, direct comparisons between studies are difficult. For instance, in one study victims rated their likelihood of violence in the next three months on a scale from zero - 10 (Bennett Cattaneo, \& Goodman, 2003) while another used a similar rating but the evaluation period was a year (Weisz, Tolman, \& Saunders, 2000). Bowen concludes in her review that victim assessments can be a valid predictor of future risk and this result was also found in a review of the 
literature by Wheller and Wire (2014), albeit from a more limited number of studies. Wheller and Wire (2014) state that the general predictive validity as indicated by AUC is .62 with a confidence interval of .61 to .62 .

Relevant here is how ratings of victim fear are elicited. The question, 'how scared do you feel?' may elicit a different response if it is asked in a cursory, disinterested manner compared with if the question follows a longer interview with rapport-building and questions about different risk factors. Further, asking questions about what kind of violence might occur, such as homicide, physical violence or psychological violence is likely to have an impact on perceptions of risk (see Nicholls, Pritchard, Reeves, \& Hilterman, 2013). An alternative method to asking direct questions about fear are questions about the victim's behaviours - as they might be good indicators of risk. Messing et al. (2014) found that highrisk victims engaged in more protective behaviours, such as asking neighbours to ring police if violence starts or packing a bag with extra clothing. Asking questions about these topics has the potential to provide a useful behavioural indicator of victim fear.

Simple predictive validity measures, such as reoffending, may underestimate how effective victims are at assessing their own risk. For instance, Gonzalez-Mendez and SantanaHernandez (2014) studied 249 women in Spain who had been in previously violent relationships. The women had been separated for an average of 1.4 years. Gonzalez-Mendez and Santana-Hernandez (2014) found that those women who felt they were most at risk took more steps to avoid their former partners than those who felt they were of lower risk. These steps reduced the offending against those who felt they were most at risk, and this confound reduces the relationship between a victim's fear and the occurrence of repeat intimate partner violence.

In other instances perceptions of risk may be simply inaccurate. In a United States study, Campbell (2004) found that only approximately one-half of the 456 women who were 
killed or almost killed by a husband, boyfriend, ex-husband or ex-boyfriend, accurately perceived their risk of being killed by their abusive partner. There could be multiple reasons for inaccurate perception of risk. Some people may under-estimate their risk because they have substance abuse problems (Vatnar, Friestad, \& Bjørkly, 2017), or because a combination of factors such as PTSD, depression and fear prevent them from assessing their risk accurately (Salcioglu, Urhan, Pirinccioglu, \& Aydin, 2017). Of course, an additional challenge in asking victims about their fear is that some victims do not co-operate with the police (e.g., Myhill, 2017). Victim fear is an important factor to consider with regards risk assessment but in many instances will also need some form of supplementary risk assessment.

Summary. Taken as a whole, all three approaches seem to have some validity and practical use. One advantage of the B-SAFER over the ODARA is that it identifies 'dynamic' factors - factors that can be changed. For example, 'negative attitudes towards domestic violence' and 'mental health problems' are dynamic factors that can be changed to reduce risk, potentially. In contrast static factors cannot be changed. For example, static risk factors such as 'prior sentence to a term of 30 days or more' or 'has a prior failure on conditional release including bail' cannot be changed once they have happened and offer no target for an intervention. In reality, however, any intervention with an offender is likely to need a more thorough risk and needs assessment than is possible by front line police at an incident of intimate partner violence.

\section{Intimate Partner Homicide}

With regards the most serious form of intimate partner violence, homicide, the picture with regards risk assessment is unclear. Most studies have scored risk factors in homicides retrospectively after a homicide has been committed. A key methodological problem is that 
much more information is available to researchers after a homicide than is available to police beforehand. One study compared the ODARA and B-SAFER for 40 homicides that were analysed concerning the information available to police beforehand. This study showed that the ODARA was slightly better than the B-SAFER at predicting homicides but the difference was small (Olszowy, Jaffe, Campbell, \& Hamilton, 2013).

There are only two studies, both unpublished, that have looked at police officers' ability to predict homicide in ahead of the attack (Chalkley, 2015; Thornton, 2011). Chalkley (2015) looked at the DASH and how it related to serious intimate partner violence in an English County. Serious intimate partner violence was identified as murder, attempted murder, manslaughter and grievous bodily harm with intent, in an intimate partner context. The majority of cases were of grievous bodily harm with $10 \%$ being homicide. One hundred and seven serious cases were identified and of these 47 perpetrators had no contact with police concerning intimate partner violence in the previous seven years - although it appears many perpetrators had been in contact with police for other crimes. Of the 67 who had previous contact with police, with regards intimate partner violence, only 22 had been previously risk assessed with the DASH as being high risk, suggesting the DASH was not accurately identifying all the serious offenders (for similar findings and methodology see also, Thornton, 2011). Chalkley (2015) also points out that of 12,301 intimate partner violence offenders in his sample identified as high risk, only 22 went on to commit serious violence. Relatedly, Messing, Campbell, Wilson, Brown, and Patchell (2017) found the Lethality Screen, an 11-item version of the Danger Assessment, was good at predicting all those that experienced near-lethal violence but again included a large number of false positives - people who were identified as in danger who did not go on to experience near lethal violence. Whilst these findings could be interpreted as negative, meaning that the risk 
assessments are inaccurate, it could also mean that something is being done by police and others to reduce risk, a positive finding.

\section{Are they violent generally, or is their violence exclusive to the intimate partner violence?}

While the focus so far has been on the risk of future intimate partner violence, a key additional issue is whether domestically violent men specialise in intimate partner violence. This is important because if a man is violently offending against his partner, and against other people more broadly, this may allow a different response than if he were offending against his partner (or his previous partners) exclusively. Potentially, police responses that do not rely on the offender's partner, or former partner, giving evidence could be used to prosecute the offender for other offences. Further, if a domestically violent man is also committing other serious offences, this may increase the likelihood of him being admitted into a treatment programme (e.g., to reduce drug and alcohol problems).

Research by Richards, Jennings, Tomsich, and Gover (2013) followed up 317 domestically violent men over a ten-year period. They found that more of the high-rate domestically violent men were also committing high numbers of other offences as well (7.3\%) than were high-rate intimate partner violence offenders exclusively but not committing many other offences (5.4\%). Andrews and Bonta (2017) argue that many intimate partner violence offenders share the same characteristics as violent offenders more generally. Indeed, they point out that Hanson, Helmus, and Borugon (2007) showed that risk assessment for violence generally showed similar levels of prediction to those developed for intimate partner violence. This does not mean that there are no men who only use intimate partner violence, they certainly do exist (again see Holtzworth-Munroe \& Stuart, 1994), but it does indicate that for many men, intimate partner violence is one part of a broader constellation of violence and offending. The implication of this is that only focusing on intimate partner 
violence risks missing a great deal of other offending, other needs of the offender, and opportunities to prosecute.

\section{Practical aspects of applying intimate partner violence risk assessment to policing}

Risk assessment will only be effective if police are able to use the tools and believe they work. As an illustration of this point, Trujillo and Ross (2008), in a sample of Australian police officers, found that the action officers took was related to their perception of the risk to the victim (for similar findings see Storey et al., 2014). Therefore, if police officers believe risk assessment tools are using items that police think genuinely predicts risk, and that the tools work, they are more likely to rely on them. In turn, this means that knowing what police believe is relevant to risk is critical to how risk assessment tools are used.

Robinson, Pinchevsky and Guthrie (2016a) surveyed 720 British and American police officers. They found that officers were largely in agreement with each other about the key risk factors concerning future intimate partner violence. These key factors were using or threatening to use a weapon; strangulation; physical assault resulting in injury; sexual assault; and, escalation of abuse. There were also some factors that many police, but not all, felt were important. For instance, jealousy and controlling behaviour was viewed as very/extremely important by $75 \%$ of respondents. When taken as a whole, this study indicated that most police officers identify the factors that are included in risk assessment tools like the ODARA and B-SAFER as relevant and important. This should mean that police feel the risk factors are justified (for similar findings with regards victim support workers, especially around high-risk people see Robinson \& Howarth, 2012). Similarly, Ward-Lasher, Messing, Cimino, and Campbell (2018) found that police decisions to arrest were related to independent risk ratings of the DA, even though the DA was not being used by the officers at the time of arrest. This again suggests that police officers have at least somewhat consistent 
ideas of risk as those suggested by risk assessment tools and in turn suggests police might be receptive to using the items included in evidence-based risk assessment tools.

More direct evidence is available about what police think about risk assessment tools. Campbell, Gill, and Ballucci (2018) surveyed 159 Canadian police officers. Of respondents, $73.5 \%$ rated risk assessment tools as somewhat to extremely helpful and $67.4 \%$ of participants said they would administer and use a risk assessment screening tool themselves if they were trained sufficiently. However, $32.6 \%$ of participants said they would not use such a tool even with training. Further analysis showed that those who were least supportive or risk assessment were young and inexperienced officers. Their youth and lack of experience meaning, presumably, that they were the officers most likely to need guidance. Similar findings were shown by Robinson, Myhill, Wire, Roberts, and Tilley (2016) in surveys of British police officers, from three police services, who had used the DASH. Between $77 \%$ and $87 \%$, across services, endorsed the item that using the DASH, 'helps get the right information from victims', and $79 \%$ to $87 \%$ felt that its use had improved police responses to intimate partner abuse. Finally, in a study of 544 police officers in Arizona, more than half of officers agreed that it is important to assess risk for homicide at every intimate partner violence incident (Ward-Lasher, Messing, \& Hart, 2017).

Robinson, Myhill, Wire, Roberts, and Tilley (2016) conducted a number of interviews with police who had used the DASH. There was concern about the length of the DASH and the difficulty in eliciting detailed personal information from victims. These views are echoed in a study of using an intimate partner violence risk assessment tool in the United States (Grant \& Cross-Denny, 2017). For instance, one officer stated:

I get two or three questions, then they realize this is probably going to screw over their husband so they don't want to answer any more questions. (p.8)

Another added: 
They see us coming in as cops making the arrest and doing the criminal stuff and all of a sudden you're asking personal questions and most of the time they're like 'I don't want to do that, just leave me alone'. (p.9)

An important aspect of intimate partner violence risk assessment, as touched-on earlier, is determining if police have the ability to use risk assessment tools, and under what conditions. Robinson et al.'s (2016) findings indicate that police have difficulty applying the DASH reliably because of lack of training and monitoring. Indeed, there is some evidence that police may have difficulty reliably scoring risk assessment tools generally. For instance, Kropp and Hart (2000) found high predictive validity for the SARA when scored by researchers but this fell dramatically when it was scored by police officers. However, it is important to note that the SARA is not designed to be scored by police officers unlike the BSAFER which is an adaption of the SARA designed to be scored by police officers and has been shown to perform better (see previous section). The strongest evidence for police being able to use risk assessment is for the ODARA. Hilton and Ham (2015) found that the ODARA can be coded reliably and the training is quick and can be provided face-to-face or electronically.

Monitoring of performance is likely to be critical to the effective use of risk assessment tools yet studies on this topic are sparse. One exception is a study by Sebire and Barling (2016). They asked 38 experienced British, police officers to rate intimate partner violence scenarios for risk using the DASH. They found that officers were inconsistent in their ratings of risk. Further, when officers were reminded of the National guidelines for risk assessment, a third changed their risk assessment. This gives an indication of how oversight can influence decisions and how malleable risk assessments can be to outside influence.

Of course, beyond the practicalities of administering risk assessments is the question of what is done with the results. Management directions concerning how to respond have an 
impact on what is done. Johnson and Dai (2016) found that explicit directions such as written policies and rewards influenced officers' intimate partner violence arrests, indicating that policy needs to be developed around how risk assessment is used. Risk assessment is not an end in itself. Consequently, there remains a great deal more that needs to be done to understand how police can be trained and managed in risk assessment and how this should be done in practice.

Finally, there seems to be a preference amongst police for a structured professional judgement approach because police officers like to have discretion with regards the ultimate rating of risk (Diemer, Ross, Humphreys, \& Healey, 2017: Hoyle, 2008). In the context of risk assessment more broadly, however, there is debate whether professional judgment is more effective than actuarial approaches, or if it just means people override risk assessments they disagree with and reduce predictive validity (for a comprehensive discussion see Harris, Rice, Quinsey, \& Cormier, 2015)

\section{What else might be associated with risk assessment?}

Risk assessment tools have other impacts on the policing of intimate partner violence beyond risk assessment alone. When the police attend a suspected intimate partner violence incident their first requirement is to investigate if a crime has occurred. There is very limited research into how police do this. In one of the only experimental studies of police decisionmaking, Fahsing and Ask (2015) found that experienced detectives far outperformed novice police officers for a potential homicide investigation. Fahsing and Ask (2015) attributed this to the more experienced officers being able to generate more investigative hypotheses. Where this relates to intimate partner violence risk assessment is that the provision of a risk assessment tool may serve to help officers generate more hypotheses about what is happening, and what they should be investigating. For example, including risk items such as 
'strangulation' and 'controlling behaviour' may encourage police officers to investigate for these factors. With regards controlling and coercive behaviour, this might be critical because it can have a profound impact on the victim but may not be immediately apparent to police officers without probing questions (Myhill \& Hohl, 2016: Robinson, Pinchevsky, \& Guthrie, 2016b; Robinson, Myhill, \& Wire, 2017). Requiring officers to rate this factor may encourage a greater depth of investigation than would otherwise occur. Similarly, the fact that police need to record the level of fear of a victim for a risk assessment may mean that they ask this question which, otherwise, they might not.

Some additional aspects of intimate partner violence risk assessment that may have a positive impact are the fact that training in risk assessment also provides a mechanism for police to be trained in how intimate partner violence occurs and gain a greater understanding of the process that may help in their work (see Ballucci, Gill, \& Campbell, 2017). Ballucci, Gill and Campbell (2017) found that some of the police officers that they interviewed were also using the risk assessment tools to inform complainants that they were at risk and to illustrate that what they were experiencing was not 'normal'. The implication of all this is that risk assessment may have a positive impact beyond merely risk ratings.

\section{Discussion}

The use of risk assessment tools by frontline police for intimate partner violence is still in its infancy but has potential to make a massive difference to how intimate partner violence is policed. The volume of incidents that police attend means that small improvements in how police respond will make a big differences at an aggregate level. There are a number of tools available and an emerging literature suggests they can have some ability to predict risk. This is an important point worth reiterating: it is possible, to some degree, to predict risk of intimate partner violence. The most effective tools have a medium 
to good degree of validity for predicting recidivism in when conditions are optimal. There is enough empirical evidence, therefore, to warrant further, focused, research to refine risk assessment for intimate partner violence to maximise impact and effectiveness. However, as a first, basic step, there is a need to know if these risk assessment tools outperform police officers' estimates of risk based on their experience or intuition alone. There is an extensive literature in risk assessment by psychologists and psychiatrists that would suggest the risk assessment tools will out-perform experience but this basic research has not been done in the context of police and intimate partner violence (for a discussion see Skeem \& Monahan, 2011). This would seem something of an oversight.

The intimate partner violence risk assessment tools, reviewed here, have the items that police report to be important for intimate partner violence (Richards, Jennings, Tomsich, \& Gover, 2013) and frontline police do show general support for risk assessment for intimate partner violence (e.g., Campbell, Gill \& Ballucci, 2018). Nevertheless, there are other practical factors. In many instances it is not clear how reliable police are at coding these risk assessment tools. Most of the studies have that have shown predictive ability have used trained researchers but this is not the case in actual police work. Kropp and Hart (2000) have shown police perform less well than researchers perhaps because they lack the training, scrutiny and motivation to code consistently. This is a concern, as risk assessment tools may be substantially less reliable in practice than is indicated by research. Other practical matters include how long a test takes to administer. This is important for police resources but this has not been discussed in any great depth. The length of time taken to do a risk assessment seems to be a common complaint of police officers (Robinson, Myhill, Wire, Tilley, \& Roberts, 2016). Relatedly, the length of time it takes to train an officer to use a tool is important and only the ODARA has evidence to suggest quick and reliable training (Hilton \& Ham, 2015). Clearly, all this has resourcing implications. Ideally there should be research directly 
comparing the different tools that includes the practicalities involved in the administration of the tool. In an ideal world trials would directly compare the practicality and effectiveness of different tools with one another.

Some of the components of intimate partner violence risk assessment tools are amenable to automation. For instance, many risk assessment tools, including the ODARA and the B-SAFER include items that are available on police databases, such as previous incidents of violence and breach of conditional release. These items could be coded automatically, removing the scoring errors that officers might make and freeing officers up to spend more time with victims or investigating. Indeed, one police service, New Zealand Police is using this approach with anecdotal success (New Zealand Police, 2018). This may also allow for more sophisticated algorithms to be developed. For instance, different weightings can be given to items and calculated by computer. Further it may be possible to tailor risk assessments to particular environments by developing unique predictive models and updating them frequently over time to reflect changes in the environment. For example, one jurisdiction may have much greater enforcement of bail conditions than another. In turn, this may mean that the weighting of this item should be different to another jurisdiction with more lax enforcement.

Technology means that police can use an automated actuarial risk assessments at the time of a call for service followed up with assessment at by the police at the scene. Thus, police can supplement an initial risk assessment with additional, potentially dynamic information, such as imminent relationship breakdown and acute mental health problems like psychosis. Many of these assessments may be beyond the ability of front line officers - for instance, determining whether someone is psychotic or under the influence of amphetamines or whether someone is drunk, depressed, or both requires higher level psychological assessment skills than most police have (McEwan, Bateson \& Strand, 2017). Therefore, a 
way of dealing with this might be to have a tiered approach whereby high-risk people or instances where risk is uncertain, are referred to specialists for more thorough assessment. Of course risk assessments alone will have no impact if they have no influence on decisions. From a Risk-Needs-Responsivity theoretical perspective high-risk offenders should be followed-up with additional services that reduce the risk of re-offending. This point is worth repeating. Risk assessment is only useful in terms of influencing responses - accurate risk assessments in and of itself will not achieve anything unless it is used to inform a suitable response.

To conclude, when police are trained in an evidence-based risk assessment approach they can predict, to some degree, future intimate partner violence. Even under ideal conditions this ability is far from perfect and if conditions deviate from ideal, for instance because of lack of training, oversight, or time, then usefulness will be reduced. There may also be side-effects of risk assessment for intimate partner violence - the most important of which might be encouraging police to look harder at cases of alleged intimate partner violence to find the whole picture of what is going on. Risk assessment, therefore, needs to be done properly, and has tremendous potential to be a central component for policing intimate partner violence.

\section{References}

Ali, P.A., Dhingra, K., \& McGarry, J. (2016). A literature review of intimate partner violence and its classification. Aggression and Violent Behavior, 31, 16-25. DOI:

Almond, L., McManus, M., Brian, D., \& Merrington, D. P. (2017). Exploration of the risk factors contained within the UK's existing domestic abuse risk assessment tool (DASH): Do these risk factors have individual predictive validity regarding recidivism? Journal of Aggression, Conflict and Peace Research, 9, 58-68. 
Andrews, D. A., \& Bonta, J. (2017). The Psychology of Criminal Conduct (6 $6^{\text {th }}$ ed.). Routledge: Abington-on-Thames, UK.

Andrews, D. A., Bonta, J., \& Hoge, R. D. (1990). Classification for effective rehabilitation: Rediscovering psychology. Criminal Justice and Behavior, 17, 19-52.

Ariza, J. J. M., Robinson, A., \& Myhill, A. (2016). Cheaper, faster, better: Expectations and achievements in police risk assessment of domestic abuse. Policing, 10, 341-350.

Ballucci, D., Gill, C., \& Campbell, M.A. (2017). The power of attitude: The role of police culture and receptivity of risk assessment. Tools in IPV calls. Policing, 11, 242-257.

Belfrage, H., \& Strand, S. (2012). Measuring the outcome of structured spousal violence risk assessments using the B-SAFER: Risk in relation to recidivism and intervention. Behavioral Sciences \& the Law, 30, 420-430.

Bennett Cattaneo, L., \& Goodman, L.A. (2003). Victim-reported risk factors for continued abusive behavior: Assessing the dangerousness of batterers. Journal of Community Psychology, 31, 349-369.

Berk, R. A., Sorenson, S. B., \& Barnes, G. (2016). Forecasting domestic violence: A machine learning approach to help inform arraignment decisions. Journal of Empirical Legal Studies, 13, 94-115.

Bland, M., \& Ariel, B. (2015). Targeting escalation in reported domestic abuse: Evidence from 36,000 callouts. International Criminal Justice Review, 25, 30-53.

Bowen, E. (2011). An overview of partner violence risk assessment and the potential role of female victim risk appraisals. Aggression and Violent Behavior, 16, 214-226.

Campbell, J. C. (2004). Helping women understand their risk in situations of intimate partner violence. Journal of Interpersonal Violence, 19, 1464-1477. 
Campbell, J. C., Webster, D. W., \& Glass, N. (2009). The danger assessment: validation of a lethality risk assessment instrument for intimate partner femicide. Journal of Interpersonal Violence, 24, 653-674.

Campbell, M. A., Gill, C., \& Ballucci, D. (2018). Informing police response to intimate partner violence: Predictors of perceived usefulness of risk assessment screening. Journal of Police and Criminal Psychology, 33, 175-187.

Chalkley, R. (2015). Predicting serious domestic assaults and murder in Dorset.

Unpublished Masters Thesis in Applied Criminology and Police Management, Institute of Criminology, University of Cambridge.

Devries, K. M., Mak, J. Y., Garcia-Moreno, C., Petzold, M., Child, J. C., Falder, G., Lim, S., Baccchus, L. J., Engell, R. E., Rosenfeld, L., Pallitto, C., Vos, T., Abrahams, N., Watts, C. H. (2013). The global prevalence of intimate partner violence against Women. Science, 340, 1527-1528.

Diemer, K., Ross, S., Humphreys, C., \& Healey, L. (2017). A 'double edged sword': Discretion and compulsion in policing domestic violence. Police Practice and Research, 18, 339-351.

Fahsing, I. A., \& Ask, K. (2015). The making of an expert detective: The role of experience in English and Norwegian police officers' investigative decision making. Psychology, Crime and Law, 22, 1-44.

Gonzalez-Mendez, R., \& Santana-Hernandez, J. D. (2014). Perceived risk and safety-related behaviors after leaving a violent relationship. The European Journal of Psychology Applied to Legal Context, 6, 1-7.

Grant, T. M., \& Cross-Denny, B. (2017). Lethality assessment protocol: Police perceptions of a domestic violence intervention. Criminal Justice Review, 42, 384-399. 
Gregory, R. J. (2011). Psychological testing: History, Principles, and Applications (6 ${ }^{\text {th }}$ ed.). Boston: Allyn \& Bacon.

Hanson, R. K., Bourgon, G., \& Helmus, L. (2007). The Validity of Risk Assessments for Intimate Partner Violence: A Meta-Analysis. Ottawa, Ontario: Public Safety Canada.

Hanson, R. K., Bourgon, G., McGrath, R., Kroner, D., D’Amora, D. A., Thomas, S. S., \& Tavarez, L. P. (2017). A five-level risk and needs system: Maximizing assessment results in corrections through the development of a common language. Canada: Public Safety Canada.

Harris, G.T., Rice, M.E., Quinsey, V.L., \& Cormier, C.A. (2015). Violent Offenders: Appraising and Managing Risk, $3^{\text {rd }}$ Edition. : Washington: American Psychological Association.

Heyman, R. E., Kogan, C. S., Foran, H. M., Burns, S. C., Slep, A. M. S., Wojda, A. K., Keeley, J. W., Rebelloe, T. J., \& Reed, G. M. (2018). A case-controlled field study evaluating ICD-11 proposals for relational problems and intimate partner violence. International Journal of Clinical and Health Psychology, 18, 113-123.

Heyman, R. E., Slep, A. M. S., \& Foran, H. M. (2015). Enhanced definitions of intimate partner violence for DSM-5 and ICD-11 may promote improved screening and treatment. Family Process, 54, 64-81.

Hilton, N. Z., \& Eke, A. W. (2016). Non-specialization of criminal careers among intimate partner violence offenders. Criminal Justice and Behavior, 43, 1347-1363.

Hilton, N.Z. \& Ham, E. (2015). Cost-effectiveness of electronic training in domestic violence risk assessment. Journal of Interpersonal Violence, 30, 1065-1073.

Hilton, N. Z., Harris, G. T., \& Rice, M. E. (2010). Risk assessment for criminal justice, offender intervention, and victim services. Washington: American Psychological Association. 
Hilton, N. Z., Harris, G. T., Rice, M. E., Houghton, R. E., \& Eke, A. W. (2008). An in-depth actuarial assessment for wife assault recidivism: The domestic violence risk appraisal guide. Law and Human Behavior, 32, 150-163.

Hilton, N. Z., Harris, G. T., Rice, M. E., Lang, C., Cormier, C. A., \& Lines, K. J. (2004). A brief actuarial assessment for the prediction of wife assault recidivism: The Ontario domestic assault risk assessment. Psychological Assessment, 16, 267-275.

Holtzworth-Munroe, A., \& Stuart, G. L. (1994). Typologies of male batterers: Three subtypes and the differences among them. Psychological Bulletin, 116, 476-497.

Hoyle, C. (2008). Will she be safe? A critical analysis of risk assessment in domestic violence cases. Children and Youth Services Review, 30, 323-337.

Johnson, R., Gilchrist, E., Beech, A. R., Weston, S., Takriti, R., \& Freeman, R. (2006). A psychometric typology of UK domestic violence offenders. Journal of Interpersonal Violence, 21, 1270-1285.

Kropp, P. R., \& Hart, S. D. (2000). The spousal assault risk assessment (SARA) guide: Reliability and validity in adult male offenders. Law and Human Behavior, 24, 101.

Kropp, P. R., \& Hart, S. D. (2004). The development of the brief spousal assault form for the evaluation of risk (B-SAFER): A tool for criminal justice professionals. Research and Statistics Division, Department of Justice Canada: Canada.

Kropp, P. R., Hart, S. D., \& Belfrage, H. (2005). Brief spousal assault form for the evaluation of risk (B-SAFER): User manual. Vancouver, Canada: Proactive Resolutions.

Liem, M., Barber, C., Markwalder, N., Killias, M., \& Nieuwbeerta, P. (2011). Homicidesuicide and other violent deaths: An international comparison. Forensic Science International, 207, 70-76.

McEwan, T. E., Bateson, S., \& Strand, S. (2017). Improving police risk assessment and management of family violence through a collaboration between law enforcement, 
forensic mental health and academia. Journal of Criminological Research, Policy and Practice, 3, 119-131.

Messing, J. T., Campbell, J. C., Brown, S., Patchell, B., Androff, D. K., \& Wilson, J. S. (2014). The association between protective actions and homicide risk: Findings from the Oklahoma Lethality Assessment Study. Violence and Victims, 29, 543-563.

Messing, J. T., Campbell, J., Sullivan Wilson, J., Brown, S., \& Patchell, B. (2017). The lethality screen: The predictive validity of an intimate partner violence risk assessment for use by first responders. Journal of Interpersonal Violence, 32, $205-$ 226.

Messing, J. T., \& Thaller, J. (2013). The average predictive validity of intimate partner violence risk assessment instruments. Journal of Interpersonal Violence, 28, 15371558.

Myhill, A. (2015). Measuring coercive control: What can we learn from national population surveys? Violence Against Women, 21, 355-375.

Myhill, A., \& Hohl, K. (2016) The "Golden Thread" Coercive Control and Risk Assessment for Domestic Violence. Journal of Interpersonal Violence, 1-21

Myhill, A. (2017). Renegotiating domestic violence: police attitudes and decisions concerning arrest. Policing and Society, 1-17.

New Zealand Police (2018, August 14) retrieved from http://www.police.govt.nz/news/release/police-family-harm-app-recognised-nationalit-award

Nicholls, T. L., Pritchard, M. M., Reeves, K. A., \& Hilterman, E. (2013). Risk assessment in intimate partner violence: A systematic review of contemporary approaches. Partner Abuse, 4, 76-168. 
Ogloff, J. R., \& Davis, M. R. (2004). Advances in offender assessment and rehabilitation: Contributions of the risk-needs-responsivity approach. Psychology, Crime \& Law, 10, 229-242.

Olszowy, L., Jaffe, P. G., Campbell, M., \& Hamilton, L. H. A. (2013). Effectiveness of risk assessment tools in differentiating child homicides from other domestic homicide cases. Journal of Child Custody, 10, 185-206.

Quinsey, V. L., Harris, G. T., Rice, M. E., \& Cormier, C. A. (1998). The Law and public policy: Psychology and the social sciences series. Violent offenders: Appraising and managing risk. Washington, DC, US: American Psychological Association.

Richards, T. N., Jennings, W. G., Tomsich, E., \& Gover, A. (2014). A 10-Year analysis of rearrests among a cohort of domestic violence offenders. Violence and Victims, 29(6), 887-906.

Rice, M.E., \& Harris, G.T. (2005). Comparing effect sizes in follow-up studies: ROC Area, Cohen's d, and r. Law \& Human Behavior, 29, 615-620.

Robinson, A. L., \& Howarth, E. (2012). Judging risk: Key determinants in British domestic violence cases. Journal of Interpersonal Violence, 27, 1489-1518.

Robinson, A. L., Myhill, A. \& Wire, J. (2017). Practitioner (mis) understandings of coercive control in England and Wales. Criminology \& Criminal Justice 1-21.

Robinson, A. L., Myhill, A., Wire, J., Roberts, J., \& Tilley, N. (2016). Risk-led Policing of Domestic Abuse and the DASH Risk Model. What Works: Crime Reduction Research. Cardiff \& London: Cardiff University, College of Policing and UCL Department of Security and Crime Science.

Robinson, A. L., Pinchevsky, G. M. \& Guthrie, J. A. (2016a). A small constellation: Risk factors informing police perceptions of domestic abuse. Policing and Society 
Robinson, A. L., Pinchevsky, G. M., \& Guthrie, J. A. (2016b). Under the radar: Policing nonviolent domestic abuse in the US and UK. International Journal of Comparative and Applied Criminal Justice, 40, 195-208.

Salcioglu, E., Urhan, S., Pirinccioglu, T., \& Aydin, S. (2017). Anticipatory fear and helplessness predict PTSD and depression in domestic violence survivors. Psychological Trauma: Theory, Research, Practice, and Policy, 9, 117-125.

Sebire, J., \& Barling, H. (2016). Assessing the assessors: An analysis of the consistency of risk grading by police when conducting domestic abuse investigations. Policing: $A$ Journal of Policy and Practice, 10, 351-360.

Serie, C. M., van Tilburg, C. A., van Dam, A., \& de Ruiter, C. (2017). Spousal assaulters in outpatient mental health care: The relevance of structured risk assessment. Journal of Interpersonal Violence, 32, 1658-1677.

Sherman, L., Bland, M., House, P., \& Strang, H. (2016). The Felonious Few vs. The Miscreant Many. Report Submitted to Deputy Police Commissioner Stephen Brown Under the 2015 Western Australia Police Contract for Training and Development in Evidence-Based Policing with the Cambridge Centre for Evidence Based Policing, University of Cambridge, Cambridge, UK.

Skeem, J. L., \& Monahan, J. (2011). Current directions in violence risk assessment. Current Directions in Psychological Science, 20, 38-42.

Storey, J. E., Kropp, P. R., Hart, S. D., Belfrage, H., \& Strand, S. (2014). Assessment and management of risk for intimate partner violence by police officers using the brief spousal assault form for the evaluation of risk. Criminal Justice and Behavior, 41, 256-271.

Trujillo, P. M., \& Ross, S. (2008). Police response to domestic violence: Making decisions about risk and risk management. Journal of Interpersonal Violence, 23, 454-473. 
Thornton, S. (2011). Predicting serious domestic assaults and murder in the Thames Valley. Cambridge, UK: Wolfson College.

Vatnar, S. K. B., Friestad, C., \& Bjørkly, S. (2017). Intimate partner homicide in Norway 1990-2012: Identifying risk factors through structured risk assessment, court documents, and interviews with bereaved. Psychology of Violence, 7, 395-405

Ward, T., \& Beech, A. R. (2015). Dynamic risk factors: A theoretical dead-end? Psychology, Crime \& Law, 21, 100-113.

Ward-Lasher, A., Messing, J. T., Cimino, A. N., \& Campbell, J. C. (2018). The association between homicide risk and intimate partner violence arrest. Policing: A Journal of Policy and Practice.

Ward-Lasher, A., Messing, J. T., \& Hart, B. (2017). Policing intimate partner violence: Attitudes toward risk assessment and collaboration with social workers. Social work, 62, 211-218.

Weisz, A. N., Tolman, R. N., \& Saunders, D. G. (2000). Assessing the risk of severe domestic violence: The importance of survivor's predictions Journal of Interpersonal Violence, 15, 75-90.

Westera, N. J., \& Powell, M. B. (2017). Prosecutors' perceptions of how to improve the quality of evidence in domestic violence cases. Policing and Society, 27, 157-172.

Wheller, L., \& Wire, J. (2014). Domestic abuse risk factors and risk assessment: Summary of findings from a Rapid Evidence Assessment. London, UK: College of Policing. 
Table 1. Comparisons of items in the ODARA, B-SAFER and DASH. Items are themed broadly rather than items being identical across risk assessment tools.

\begin{tabular}{|c|c|c|c|}
\hline Item & ODARA & B-SAFER & DASH \\
\hline Previous incidents/contraventions & $\checkmark$ & $\checkmark$ & $\checkmark$ \\
\hline Frequency of domestic violence & $\checkmark$ & $\checkmark$ & $\checkmark$ \\
\hline Respondent history of violence & $\checkmark$ & $\checkmark$ & \\
\hline Prior sentence for jail & $\checkmark$ & & $\checkmark$ \\
\hline Prior fail of conditional release & $\checkmark$ & & \\
\hline Alcohol/drug misuse & $\checkmark$ & $\checkmark$ & $\checkmark$ \\
\hline Mental health issues & & $\checkmark$ & $\checkmark$ \\
\hline Animal cruelty & & & $\checkmark$ \\
\hline Negative Attitudes toward DV & & $\checkmark$ & \\
\hline Separation & & $\checkmark$ & $\checkmark$ \\
\hline Severity and escalation & & & \\
\hline $\begin{array}{l}\text { Significant change in circumstances } \\
\text { (including financial issues) }\end{array}$ & & & $\checkmark$ \\
\hline Employment problems & & $\checkmark$ & \\
\hline Strangulation/suffocation & & & $\checkmark$ \\
\hline Threats to kill & $\checkmark$ & $\checkmark$ & $\checkmark$ \\
\hline Use of weapons & & & $\checkmark$ \\
\hline $\begin{array}{l}\text { Controlling (and Isolating) } \\
\text { behaviour }\end{array}$ & & & $\checkmark$ \\
\hline Sexual violence & & & $\checkmark$ \\
\hline Unlawful confinement & $\checkmark$ & & \\
\hline $\begin{array}{l}\text { Victim faces at least one barrier } \\
\text { to support }\end{array}$ & $\checkmark$ & & \\
\hline Stalking & & & $\checkmark$ \\
\hline $\begin{array}{l}\text { Suicidal (aggrieved and/or } \\
\text { respondent) }\end{array}$ & & $\checkmark$ & $\checkmark$ \\
\hline Violent threats & & $\checkmark$ & $\checkmark$ \\
\hline Fear level & $\checkmark$ & & $\checkmark$ \\
\hline Resulted in injury & & & $\checkmark$ \\
\hline $\begin{array}{l}\text { Victim/offender have children } \\
\text { together }\end{array}$ & $\checkmark$ & & \\
\hline $\begin{array}{l}\text { Offender is in stepfather role in } \\
\text { this relationship }\end{array}$ & $\checkmark$ & & $\checkmark$ \\
\hline Child custody issues & & & $\checkmark$ \\
\hline Other people threatened victim & & & $\checkmark$ \\
\hline
\end{tabular}

Note: $-\checkmark$ present. 